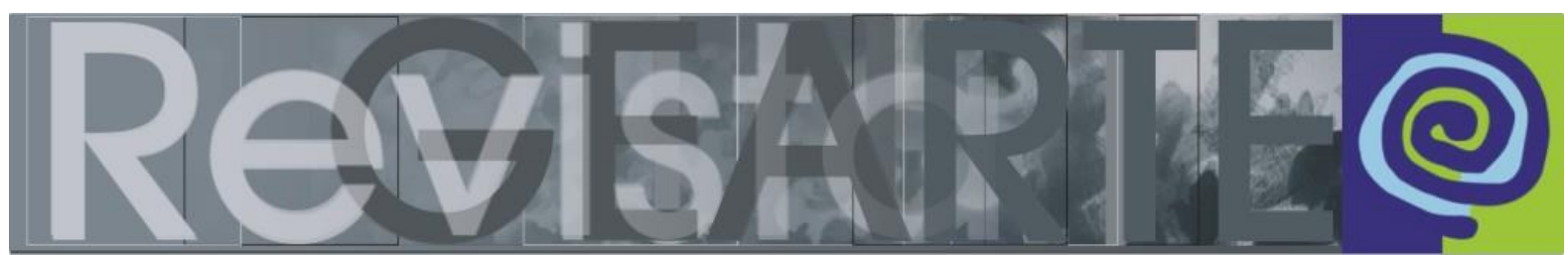

e-ISSN 2357-9854

\title{
Arte popular e espaço universitário: uma experiência educativa mediada pela reflexão filosófica
}

\author{
Selma Machado Simão (Universidade Estadual de Paulista \\ - UNESP, Rio Claro/SP, Brasil)
}

\begin{abstract}
RESUMO - Arte popular e espaço universitário: uma experiência educativa mediada pela reflexão filosófica - Este artigo apresenta as análises dos resultados de uma ação educativa realizada na Galeria de Arte do Instituto de Artes da Unicamp (GAIA) no ano de 2017. Os conteúdos teóricos e práticos desta proposta foram fundamentados nas linguagens da Arte Popular brasileira, como: lendas, danças, cantigas e a Literatura de Cordel. Tais conteúdos foram fruídos e analisados por meio de reflexões filosóficas dos autores: Michel Foucault, Mikhail M. Bakhtin e Gilles Deleuze. Assim, a mediação baseou-se no enfoque fenomenológico e na interlocução de objetos culturais inseridos no universo epistemológico de conceitos da Filosofia. Tornou visíveis as produções de diferentes grupos e seus autores no intuito de promover a criação poética e a autoria, além de evidenciar a importância da pesquisa empírica na área de educação em artes.
\end{abstract}

PALAVRAS-CHAVE

Arte popular. Criação.Filosofia.

ABSTRACT - Popular art and university space: an educational experience mediated by philosophical reflection - This article presents the analysis of the results of an educational action carried out at the Art Gallery of the Institute of Arts of Unicamp (GAIA) in the year 2017. The theoretical and practical contents of this proposal were based on the languages of Brazilian Popular Art, such as legends, dances, songs and Cordel Literature. These contents were collected and analyzed through philosophical reflections of the authors: Michel Foucault, Mikhail M. Bakhtin and Gilles Deleuze. Thus, mediation was based on the phenomenological focus and interlocution of cultural objects inserted in the epistemological universe of concepts of Philosophy. He made visible the productions of different groups and their authors in order to promote poetic creation and authorship, as well as highlighting the importance of empirical research in the area of arts education.

KEY WORDS

Popular Art. Creation. Philosophy.

\section{Introdução}

No ano de 2017, concorrendo ao processo seletivo referente ao Edital da Programação Oficial de eventos da Galeria de Arte do Instituto de Artes da UNICAMP (GAIA) foi selecionado o projeto cultural e educativo: Arte Popular, Criação e Reflexão: Percursos Poéticos e Filosóficos.A iniciativa partiu de uma integrante do Grupo de Estudos Escriarte que é conectado ao Grupo de Estudos e Pesquisas Interdisciplinares (GEPI)- Linguagens Experiência Memória e Formação pertencente ao Departamento de Educação do Instituto de Biociências da Universidade Estadual 
de Paulista (UNESP) no Campus Rio Claro em São Paulo. O principal objetivo desta proposta foi difundir e valorizar a Arte Popular brasileira em um ambiente cultural e educativo universitário. Com a intenção de facilitarseu acesso a estudantes do ensino superior, a proposta buscou contribuir com a preservação e difusão desta modalidade de arte, além de torná-la visível em um espaço que não costuma ser aderente aela. Desta forma, a ação pretendeu colaborar com a perpetuação das raízes culturais de coletividades mais afastadas da cultura dita erudita.

Assim, com o objetivo de oferecer oportunidades de reconhecimento da potencialidade da Arte Popular fomentando-a no meio acadêmico, o projeto possibilitou a fruição de variados objetos culturais populares vindos de diversas linguagens e repertórios, como: relatos e poemas da Literatura de Cordel; cantigas, descrições poéticas de lendas folclóricas regionais e urbanas e imagens de trabalhos de arte grafite e naïf. Por meio da oferta de três oficinas de Artes Visuais, com duração de 3 horas cada uma, em que foram disponibilizadas 15 vagas gratuitas para estudantes e/ou pessoas externas ao ambiente da universidade, como: professores da rede pública, educadores sociais, coordenadores pedagógicos e diretores de escolas. A inscrição foi finalizada com nove pessoas, entre elas, três estudantes do Instituto de Artes, três educadoras e um educador social da ONG Projeto Gente Nova (PROGEN) e duas professorasda rede municipal de ensino da cidade de Campinas.

Com enfoque na abordagem fenomenológicade Merleau-Ponty estas oficinas se dedicaram a desenvolver reflexões sobre a produção cultural abordada em diálogocom pensamentos extraídos de textos filosóficos clássicos erelacionados aos contextos estudados. Os autores selecionados para fundamentar as discussões foram: Michel Foucault, MikhailM. Bakhtin, Gilles Deleuze e Félix Guatarri.

Os trabalhos privilegiaram a ampliação da sensibilização, da fruição e a análise dos objetos culturais analisados. Para Maurice Merleau-Ponty (1999, p. 6) o sujeito e o que é percebido por ele, configuram uma simbiose, sendo que a percepção se realiza na experiência dos atos da existênciano mundo: [...] a percepção não é uma ciência do mundo, não é nem mesmo um ato, uma tomada de posição deliberada; ela é o fundo sobre o qual todos os atos se destacam e ela é pressuposta por eles. 
Desta maneira, além de usufruir da apreciação das produções artístico-culturais apresentadas, os integrantes participaram de tertúlias sobre os conteúdos abordados, ou seja, conversas voltadas a temas de interesses comuns paratrocarem informações e reflexões e debaterem posições. Oportunidades que permitiram a realização de discussões a respeito dos objetivos e veiculação da Arte Popular na contemporaneidade. Nesta ocasião foram estudados os pensamentos dos textos clássicos dos autores mencionados anteriormente com o propósito de relê-los a partir seu contato, análise e discussão.

Após realizarem os estudos teóricos de cada oficina os participantes realizaramuma atividadeespecífica de Artes Visuaisexplorando além da expressão imagética, também a expressão escrita sobre os conteúdos analisados e discutidos. Esta atividade dedicada à produção prática foi planejada para proporcionar o desenvolvimento do processo criativo tendo em vista oaperfeiçoamento da sensibilidade e o favorecimento deconexõesdas criações pessoais formais relacionadas a cada um dos temas abordados.

A partir das produções concluídas, cada participante pôde comentar como se deu sua experiênciasendo convidado a expressar ideias relacionadas aos conhecimentos adquiridos, assim como avaliar a proposta desenvolvidae comentar como se deramos percursos das etapas de seu processo criativo.

\section{As especificidades das oficinas}

A opção metodológica utilizada para a realização das oficinas motivou os integrantes a construir uma atitude reflexivamanifestando formas críticas do pensamento sobre questões importantes, como: preconceito, resistência, intolerância, produção cultural local e global, a influência da indústria cultural na concepção sobre o que é arte nas comunidades, e outros pontos controversos. A experiência formadora que as discussões sobre a Arte Popular propiciaram ao grupo foram capazes de conectar as pessoas apesar de seus diferentes contextos de vidas. O ambiente educacional fomentado permitiu que a pluralidade das expressões dos participantes fosse respeitada, assim todos foram incentivados a manifestar seus pensamentos 
livremente. As práticas cotidianas configuram relatos baseados em gestos e narrativas singulares que incluem o espaço e o tempo vividos no mundo. Os estudantes, professores, educadores e profissionais da Educação que participaram das oficinas denotaram a necessidade de expressar suas ideias e reclamaram que havia poucos espaços em suas vidas para manifestarem falas significativas relacionadas às suas práticas.

No tocante às produções em artes realizadas durante os andamentos das oficinas houve também uma energia de sincronicidade e interdependência, pois essas se transformaram em objetos culturais sensíveis, cognitivos e comunicantes sobre os quais todos opinavam na ocasião da apreciação coletiva.

A seguir serão elencadas as proposições de cada uma das oficinas e suas respectivas ações e singularidades:

1 - A primeira oficina obteve o título: Lendas brasileiras, imagens e escritos: a (re)criação do imaginário e pretendeu desenvolver reflexões a respeito das lendas rurais e urbanas brasileiras e seus processos de origem, reformulação e propagação em confluência aos conceitos de "fábula" e "ficção" de Michel Foucault (2009, p. 210). Também se voltou a propiciar aos participantes uma vivência ativa e criadora a partir da exploração do desenho a carvão e pela técnica da escrita criativa elaborando breves escritos relacionadas à temática abordada, incluindo o caráter simbólico do folclore e o aspecto mítico das lendas.

Além de algumas lendas rurais e urbanas trazidas como exemplos, o grupo teve a oportunidade de discutir uma figura misteriosa da atualidade criada por Banksy, que desde os anos 80 vem desenvolvendo um trabalho perspicaz e impactante pautado pela crítica política e social. O artista utiliza a técnica do estêncil (molde vazado) pois assim pode concluir rapidamente seus trabalhos antes que a polícia chegue ao local da interveção. Até o momento, ninguém conseguiu comprovar sua identidade e com esta performance criou sua própria lenda.

A discussão gerou material para poemas e pequenos textos criativos. 
Figura 1 - Foto tirada durante a atividade prática da oficina (2017)

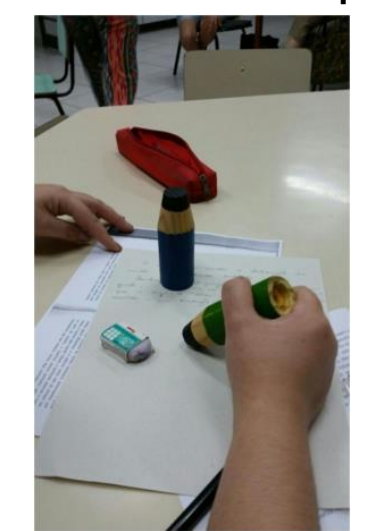

Fonte: Arquivo da autora.

Dentre as formas narrativas apresentadas, tanto relacionado ao material imagético e teórico trazido para a mediação educativa quanto sobre a produção visual e escrita realizada pelos participantes, as reflexões a respeito das considerações de Michel Foucault sobre fábula e ficção auxiliaram na compreensão do grupoa respeito dos meandros que permeiam a construção do pensamento da criação lendária. O autor faz uma distinção clara entre estes dois conceitos e explica que fábula traduz o que é contado, ou seja, descreve episódios, personagens e funções que eles exercem na narrativa, além dos acontecimentos. Em se tratando do termo ficção, leva-se em conta a posição e atitude daquele que conta a história e a orientação da qual se vale para desenvolvê-la (FOUCAULT, 2009, p. 210).

Michel de Certeau apresenta o conceito fábula através de outra perspectiva, já que menciona uma ciência da fábula que trata da:

[...] palavra selvagem, religiosa, louca, infantil ou popular - assim como se elaboram há dois séculos através de discursos como a etnologia, as "ciências religiosas", a psiquiatria, a pedagogia e os procedimentos políticos ou historiográficos visando introduzir na linguagem autorizada a "vOz do povo" (CERTEAU, 1994, p. 253).

No tocante à ficção, não é mais a palavra que importa e sim a condução da narrativa, ou as diversas formas de condução pelas quais ela é contada.

[...] postura do narrador em relação ao que ele narra (conforme ele faça parte da aventura, ou a contemple como um espectador ligeiramente afastado, ou dela esteja excluído e a surpreenda do exterior), presença ou ausência de um olhar neutro que percorra as coisas eas pessoas, assegurando sua descriçãoobjetiva; engajamento de toda a narrativa na perspectiva de um personagem, de vários, sucessivamente, ou de nenhum, em particular; 
discurso repetindo os acontecimentos a posteriori ou duplicando-os à medida que eles se desenrolam etc. (FOUCAULT, 2009, p. 210).

Consequentemente, nas lendas apresentadas aos integrantes foi possível localizar o entrecruzamento de espaços de ficção que estão também nas narrativas orais como explicitado por Michel de Certeau (1998, p. 152-154), pois segundo o autor, a apropriação da língua falada pelas pessoas se manifesta na expressão do falar em quadros figurativos que são "histórias" exemplares e em quadros analíticos ou descrições teóricas. Nela se localizam hesitações, abreviações, desvios, ditos populares e memórias, ou modos de pontuar a narrativa que foram definidos por Certeau como golpes estratégicos. Para ele, os relatos orais promovem o estilo das táticas pertencentes à arte de dizer que difere do conteúdo que é dado a conhecer ao ouvirmos o locutor.

Michel Foucault (2009, p. 210) elucida que a fábula elenca seus elementos em certa ordenação, enquanto a ficção tece uma espécie de teia entre as relações estabelecidas valendo-se do próprio discurso entre o personagem que "fala e aquele do qual ele fala". Para o autor existem vozes por trás da fábula, sendo que estas vozes estabelecem conexões de jogos e lutas, e são elas que delineiam a trama da ficção.

O grupo discutiu como estas ficções que em constante rememoração seguem se transformando e consequentemente se recriando nas mentes pelos jogos simbólicose culturais. Foucault deduz que "a obra se define menos pelos elementos da fábula ou por sua ordenação que pelos modos da ficção, indicados como que de viés pelo próprio enunciado da fábula"(FOUCAULT, 2009, p. 210).

Celebrando a vida, cada lenda rural ou urbana acessa variados tipos de públicos para seguir sendo memorizada coletivamente e relacionar-se com passagens marcadas por encruzilhadas fictícias interpostas por critérios não convencionais e não hierárquicos. Ao dissertar sobre os modos de proceder da criatividade cotidiana pelos indivíduos, Michel de Certeau (1998, p. 40-42) relata que os mesmos se encontram presos nas redes de vigilância, porém não conformados com ela a não ser para subvertê-la alterando-a. Criativamente articulam uma multiplicidade de modos que se 
configuram como táticas bricoladoras direcionadas a formar uma rede antidisciplinadorarelacionada ao consumo e contra a dominação.

2 - A segunda oficina intitulada: Ensaios escritos e imagéticos inspirados na Literatura de Cordel visou o reconhecimento de objetos culturais advindos deste tipo de literatura, além de propor a produção de imagens, contos, poemas e músicas tendo em vista as particularidades poéticas próprias desta linguagem expressiva. A vivência estética e a produção desenvolvida foram discutidas a partir do conceito de "literatura menor" de Gilles Deleuze e Félix Guattari (1978, p. 25). As experiências em Artes Visuais exploraram processos semelhantes ao da gravura utilizando diversos suportes rígidos para a feitura das matrizes e foram desenvolvidas através dos seguintes materiais: nanquim, giz de cera e grafite.

Inicialmente os participantes tiveram acesso à poesia da Literatura de Cordel, com poemas como este:

Luana, que é voluntária,

Traz na mente o esplendor,

Traz o brilho das estrelas,

Traz na mão sempre uma flor.

Os poetas desta casa,

Saberão Ihes dar valor."

(PINHEIRO, 2017)

Figura 2 - Foto tirada durante a atividade prática da oficina (2017)

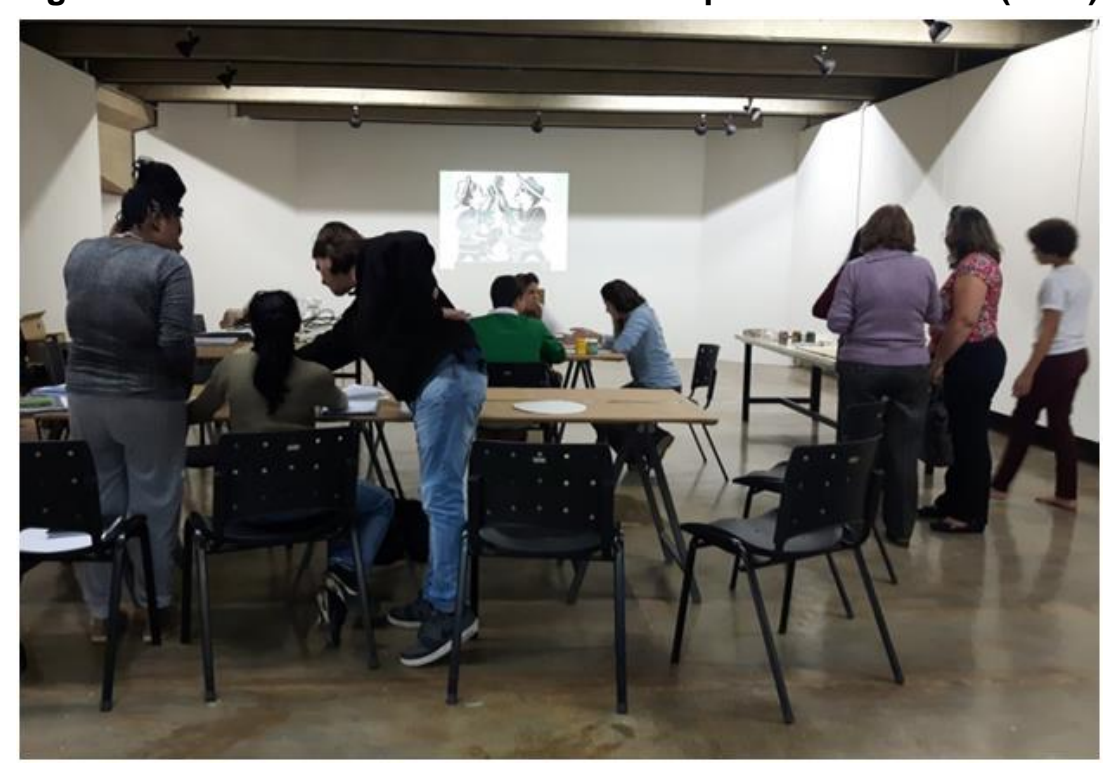

Fonte: Arquivo da autora. 
Como informam as histórias dos poetas repentistas e romanceiros, esta modalidade poética foi recriada em nosso país a partir do contato com a Literatura de Cordel lusitana apesar das dificuldades, pois a realidade brasileira do século XVIII sofria com o analfabetismo e com a escrita pouco difundida (ABREU, 1999). Segundo a Academia Brasileira de Literatura de Cordel (ABLC) surgiram inúmeras formas de poetizar, como exemplos: a parcela ou verso de quatro sílabas, o verso de cinco sílabas, as estrofes de quatro versos de sete sílabas, as sextilhas, as setilhas, as estrofes de sete versos de sete sílabas, os oito pés de quadrão ou oitavas, as décimas com dez versos de sete sílabas,o martelo agalopado, a estrofe de dez versos de dez sílabas, o martelo de seis versos, o galope à beira mar com versos de onze sílabas e por fim, a meia quadra ou versos de quinze sílabas (ABLC, 2017). A Academia informa ainda que: "os textos dos autores contemporâneos, apresentam um cuidado especial com a uniformização ortográfica, com o primor das rimas, com a beleza rítmica e com a preciosidade sonora" (ABLC, 2017). Os cordelistas são escritores do cotidiano e muitas vezes compõem seus versos com humor satirizando cenas de suas próprias vidas. Também são artesãos porque além de poemas apresentam seus trabalhos por meio arte da Xilogravura ilustrando-as com muita dificuldade de recursos.

Posteriormente a esta troca de informações e para que o grupo fosse direcionado a discutir a Literatura de Cordel, através do conceito "literatura menor" de Deleuze e Guatarri, foram introduzidos alguns pensamentos importantes destes autores. Um deles relativo à procedência deste tipo de literatura, pois enquanto analisavam a obra de Kafka, trouxemos Gilles Deleuze e Félix Guattari que defendem que "uma literatura menor não pertence a uma língua menor, mas, antes, à língua que uma minoria constrói numa língua maior" (1978, p. 25).

Segundo os autores as características da literatura menor são:

a. Desterritorialização da língua.

Para Maria Cristina Batalha, grupos ou subgrupos étnicos, raciais ou culturais que sofrem processos de marginalização acabam operando a ação de se 
desterritorializar, pois são submetidos a um "deslocamento provocado por uma descaracterização cultural, em função do espaço e da língua" (2013, p. 115).

b. Ligação do individual com o imediato político.

Gilles Deleuze e Félix Guattari (1978, p. 26) afirmam que o caráter individual das chamadas "grandes" literaturas inexiste no contexto da literatura menor, já que a conotação coletiva predomina em um bloco de um espaço amplo. Portanto, neste tipo de produção literária não há lugar para ideias compartimentadas e intransferíveis. Os poemas criam espaços de liberdade para serem compartilhados e seguem influenciando formas de comunicações estéticas e políticas entre seus pares.

\section{c. Agenciamento coletivo de enunciação.}

Na literatura menor o campo político domina todas as instâncias:

[...] o que o escritor diz sozinho já constitui uma ação comum, e o que diz ou faz, mesmo se os outros não estão de acordo, é necessariamente político. $O$ campo político contaminou o enunciado todo. Mas, sobretudo, mais ainda, porque a consciência coletiva ou nacional é "a maior parte das vezes inativa na vida exterior e continuamente em vias de desagregação". É a literatura que se encontra carregada positivamente desse papel e dessa função de enunciação coletiva e mesmo revolucionária: a literatura é que produz uma solidariedade ativa apesar do ceticismo (DELEUZE, GUATTARI, 1978, p. 27).

Após as análises destes tópicos o grupo discutiu as ideias de Michel de Certeau (1998, p. 42) sobre cultura popular, sendo mencionado nos debates que quando o autor explica que a literatura chamada "popular" é em sua essência uma "arte de fazer" algo específico, refere-se também a um agir direto que se destina à ação de combinar e utilizá-la como um consumo. Nestas análises foram comentados os caracteres criativo e subversivo que a chamada produção literária marginal é capaz de trazer à tona. Como explica Michel de Certeau:

Mil maneiras de jogar/desfazer o jogo do outro, ou seja, o espaço instituído por outros, caracterizam a atividade, sutil, tenaz, resistente, de grupos que, por não ter um próprio, devem desembaraçar-se me uma rede de forces e de representações estabelecidas. Tem que fazer "com". Nesses estratagemas de combatentes existe uma arte dos golpes, dos lances, um prazer me alterar as regras do espaço opressor (CERTEAU, 1998, p. 79). 
Também foi levantada a seguinte questão: Se a literatura menor só é menor porque vem de uma minoria e não porque é inferior à literatura clássica porque ainda é discriminada por setores da crítica e por algumas parcelas do público? Presumiu-se então, que a Literatura de Cordel apesar de ser reconhecida pelo Instituto do PatrimônioHistórico e Artístico Nacional (Iphan) como patrimônio cultural imaterial brasileiro é ainda vista com preconceito porque estes julgamentos geralmente vêm de interpretações referenciadas nos cânones da cultura erudita. O grupo reafirmou a ideia que é necessário defender a Literatura de Cordel como sendo uma produção cultural tão valorosa quanto a todas as outras categorias literárias.

3 - A terceira e última oficina obteve o título: $A$ reconstrução da memória: Cantigas e Danças Populares de Campinas e buscou relacionar a discussão teórica embasada no conceito de "polifonia de vozes" e "alteridade" de Mikhail Bakhtin (BAKHTIN, 1997, p. 392). Nesta oficina possibilitou-se o reconhecimento de um repertório de cantigas e danças populares da região de Campinas e arredores apresentando grupos de danças, cantadores e violeiros. Os integrantes também mencionaram outros grupos de danças conhecidos por eles. Para o desenvolvimento dos trabalhos foram separadas três duplas e um trio de pessoas com o intuito de criarem uma cantiga e posteriormente apresentarem para o grupo. Os participantes destas duplas também realizaram uma produção em Artes Visuais em desenho com giz de cera, lápis de cor e da técnica dapintura a guache. Foi solicitado que as imagens produzidas fossem elaboradas com o propósito de ilustrar a cantiga que fosse apresentada por eles. Para isso, utilizaram o que estava disponível para marcar o ritmo e ressaltar o refrão de suas cantigas. 
Figura 3 - Foto tirada durante a oficina (2017)

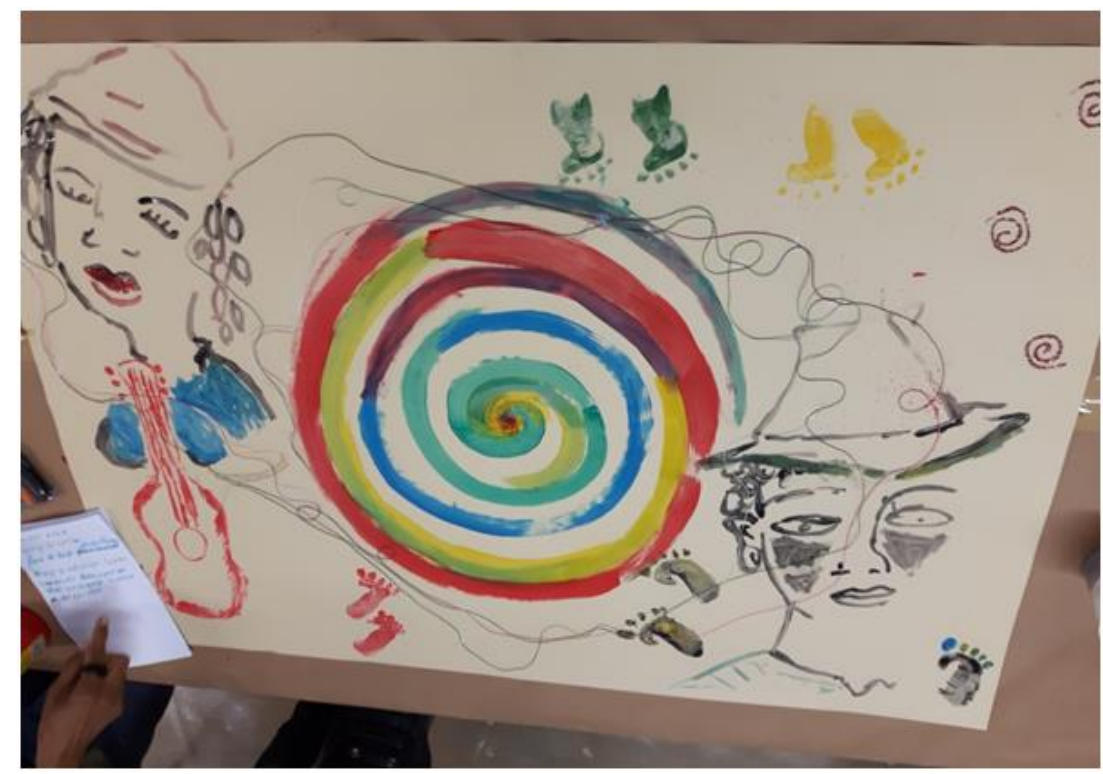

Fonte: Arquivo da autora.

Ao tratarmos do conceito de "polifonia" proposto para fomentar o debate nesta oficina, analisamos a escrita desenvolvida de forma colaborativa que privilegia as muitas vozes contidas nos seus dizeres e nas formas de dizer das cantigas populares.Mikhail Bakhtin afirma que Dostoievski foi um grande polifonista porque teve a sensibilidade de perceber o emaranhado das lutas de opiniões e de ideologias propiciando a natureza inacabada do diálogo, como explica a seguir: "O caráter inacabável do diálogo polifônico (diálogo acerca das grandes questões). São individualidades inacabáveis que travam semelhantes diálogos e não sujeitos psicológicos" (BAKHTIN, 1997, p. 392).

O samba de Umbigada foi um dos exemplos de danças populares apresentados nesta oficinacomo uma dasmuitas contribuiçõesda cultura africana trazidas para a nossa cultura. Além disso, a Umbigada é uma das tradutoras deste sentimento de natureza polifônica inacabada citada por Bakhtin. Originada por escravos africanos através de muitas vozes compartilhadas, constituiu-se como um exemplo do exercício da memória coletiva permanentemente preservada e valorizada apesar das arbitrariedades dos muitos sistemas de categorizações e preceitos discriminatórios. Muito difundida no interior paulista e em especial na cidade de Campinas, a Umbigada foi criada no contexto sócio-histórico-cultural do final do século XIX e início do XX. Posteriormente foi proibida pelos padres e fazendeiros por ser 
considerada libidinosa, já que eram incapazes de entender seus movimentos que se reportavam às práticas culturais antigas da África que homenageavam a deusa da fertilidade (SIMSON, 2005). Porém com o passar do tempo, os grupos puderam encontrar formas de preservar esta dança.

Este caráter polifônicoencontrado na dança se coaduna ao conceito de "alteridade", também defendido por Bakhtin. Um pensamento relativo à preocupação do enunciado do outro e de sua palavra em todos os discursos no sistema da língua. Além de muitas outras asserções, Bakhtin menciona a presença de uma fusão orgânica equalizando no mesmo plano de valores a dimensão da existência do outro e o que este considera seu próprio dever de ser, e assim sendo, a alteridade funciona como um componente de relações entre as consciências (BAKHTIN, 1997, p. 317). autor também ressalta as subjetividades presentes neste sentimento que preservam suas particularidades apesar de configurarem-se de maneira plural.

\begin{abstract}
Nossa fala, isto é, nossos enunciados (que incluem as obras literárias), estão repletos de palavras dos outros, caracterizadas, em graus variáveis, pela alteridade ou pela assimilação, caracterizadas, também em graus variáveis, por um emprego consciente e decalcado. As palavras dos outros introduzem sua própria expressividade, seu tom valorativo, que assimilamos, reestruturamos, modificamos (BAKHTIN, 1997, p. 314).
\end{abstract}

Foi então concluído pelo grupo que as produções culturais e artísticas populares analisadas durante as oficinas vão muito além das verdades fabricadas e condicionadas pelos "domínios de saber" disciplinados nas relações de poder mencionadas por Michel Foucault (1995, p. 32). Seus conteúdos compostos livremente, além de se contraporem a direcionamentos limitadores e preconceituosos, exercem também um enfrentamento capaz de expressar subjetividades individuais e coletivas. Ao valorizar o direito de reconhecer-se a si e ao seu grupo, além de suas práticas culturais desenvolvidas fora das formas naturalizadoras, estas formas culturais postulam meios expressivos de resistência aos padrões de gostos impostos nas esferas tradicionais. Com sua energia transformadora, seus modos de expressão extrapolam seus próprios bloqueios, estabelecendo modos de apresentar-se e passíveis de expor saídas da opressão. Segundo Michel Foucault, menos importante do que saber quem nós somos é mais profícuo "[...] recusar o que somos. Devemos 
promover novas formas de subjetividades refutando o tipo de individualidade que nos foi imposta" (1994, p. 232).

\section{Considerações Finais}

A proposta buscou a ampliação dos sentidos lúdicos, manifestações simbólicas e reflexões filosóficas capazes de valorizar as tradições populares em espaços nos quais estas tradições têm pouca penetração.

As ações foram também voltadas a ampliar os processos de recepção, percepção e expressão dos participantes, envolvendo positivamente instâncias da cognição e da emoção que influem diretamente na liberação das capacidades criadoras da escrita, da leitura, do desenho e da pintura.

Os textos escolhidos para basear os trabalhos que foram selecionados cuidadosamente alcançaram o objetivo de possibilitar uma vinculação de aderência pertinente aos conteúdos culturais trazidos para serem debatidos através de um olhar tanto filosófico quanto poético.

Como mencionado anteriormente neste texto, durante os trabalhos, o grupo criou espaços para refletir e discutir sobre como as produções artístico-culturais populares que margeiam os discursos oficiais e acabam sendo esquecidas ou desvalorizadas e manifestou uma ideia que defende estas produções sem hierarquizações, considerando-as simultâneas e dialógicas com todo o material cultural produzido no seu tempo.

Estas produções estabelecem relações poéticas, estéticas e éticas que reúnem saberes livres que circulam em ressonância e resistência.Trazer esta experiência para o âmbito da universidade configurou uma forma de salvaguardar, aclamar e amparar a Arte Popular, além de suas invenções, seus modos de produção, seus artistas, sua veiculação, sua circulação e seu consumo no sentido de impactar paradoxalmente com seu apagamento. Levando em conta também que estes artistas expressam em suas criações discursos sociopolíticos que os reafirmam como sujeitos pertencentes 
a um lugar com espaço e um tempo na história e que através de seus trabalhos apropriam-se de si mesmos.

\section{Referências}

ABREU, Márcia. História de cordéis e folhetos. Campinas: Mercado de Letras, 1999.

ACADEMIA BRASILEIRA DE LITERATURA DE CORDEL - ABLC. Métricas. Disponível em: $<$ http://www.ablc.com.br/o-cordel/metricas-2>. Acesso em: 20 mai. 2017.

ACADEMIA BRASILEIRA DE LITERATURA DE CORDEL - ABLC. Versos soltos. Disponível em: $<$ http://www.ablc.com.br/versos-soltos/>. Acesso em: 20 mai. 2017.

BAKHTIN, Mikhail. A cultura popular na ldade Média e no Renascimento: o contexto de François Rabelais. 5. ed. São Paulo: Hucitec/AnnaBlume, 2002.

BAKHTIN, Mikhail. Apontamentos 1970-1971. In: Estética da criação verbal. 2. ed.. São Paulo: Martins Fontes, 1997. p. 370-398.

BAHTKIN, Mikhail. Formas de tempo e de Cronotopo no Romance: Ensaios de poética histórica. In: BAHTKIN, Mikhail. Questões de literatura e de estética: a teoria do romance. Trad. Aurora Fornoni Bernadini et al. 3. ed. São Paulo: Ed. UNESP, 1993. p. 211-362.

BAKHTIN, Mikhail. O todo significante do herói. In: Estética da criação verbal. 2. ed. São Paulo: Martins Fontes, 1997. p. 153-198.

BATALHA, Maria Cristina. O que é uma Literatura Menor? In: Revista Cerrados no 35 . Revista do Programa de Pós-Graduação em Literatura, 2013. p 115-134. Disponível em: <http://periodicos.unb.br/index.php/cerrados/article/view/10923/pdf_9>. Acesso em: 20 mai. 2017.

CERTEAU, Michel de. Invenção do cotidiano: Artes de fazer. 3 ed. Petrópolis, RJ: Vozes, 1998.

DELEUZE, Gilles; GUATTARI, Félix. O que é uma literatura menor? In: DELEUZE, Gilles; GUATTARI, Félix. Kafka: para uma literatura menor. Rio de Janeiro: Imago, 1978. p. 25-42.

DELEUZE, Gilles. Uma conversa, o que é, para que serve? In: Diálogos. São Paulo: Editora Escuta, 1998. p. 9-27.

FOUCAULT, Michel. La Verdad y las Formas Jurídicas. Barcelona: Gedisa, 1995.

FOUCAULT, Michel. Le sujet et le pouvoir. In: FOUCAULT, Michel. Dits et Écrits IV - 1980-1988. Paris: Gallimard, 1994. p. 222-242.

FOUCAULT, Michel. Por trás da fábula. In: Estética: literatura e pintura, música e cinema. Rio de Janeiro: Forense, 2009. p $210-218$.

MERLEAU-PONTY, Maurice. Fenomenologia da percepção. Tradução Carlos Alberto Ribeiro de Moura. 2 ed. São Paulo: Martins Fontes, 1999.

SIMSON, von Olga R. de M. Samba paulista: experiências, estórias e memórias da estratégica trajetória negra construída em nosso estado. O samba de Umbigada e o samba de Bumbo. Palestra F.E. e C.M.U./UNICAMP, 2005. 


\section{Selma Machado Simão}

É graduada em Licenciatura em Educação Artística com Habilitação em Artes Plásticas pela Faculdade de Belas Artes de São Paulo. Fez Especialização em Arte e Tecnologia pela Faculdade de Belas Artes de São Paulo e Especialização em Expressões Criativas pela Faculdade de Ciências da Saúde. Mestre em Artes Visuais pelo Instituto de Artes da Unesp e Doutora em Educação pela Faculdade de Educação da Universidade Estadual de Campinas (FE/Unicamp). Realizou Pós-doutorado em Educação pela Unesp de Rio Claro (2016). Pesquisadora Unesp Rio Claro.

Email: selma.msimao@gmail.com

Currículo: http://lattes.cnpq.br/6227204383079210

Recebido em 18 de julho de 2018 Aceito em 5 de dezembro de 2018 